\title{
Comparison of the fecal microbiota of two free-ranging Chinese subspecies of the leopard (Panthera pardus) using high-throughput sequencing
}

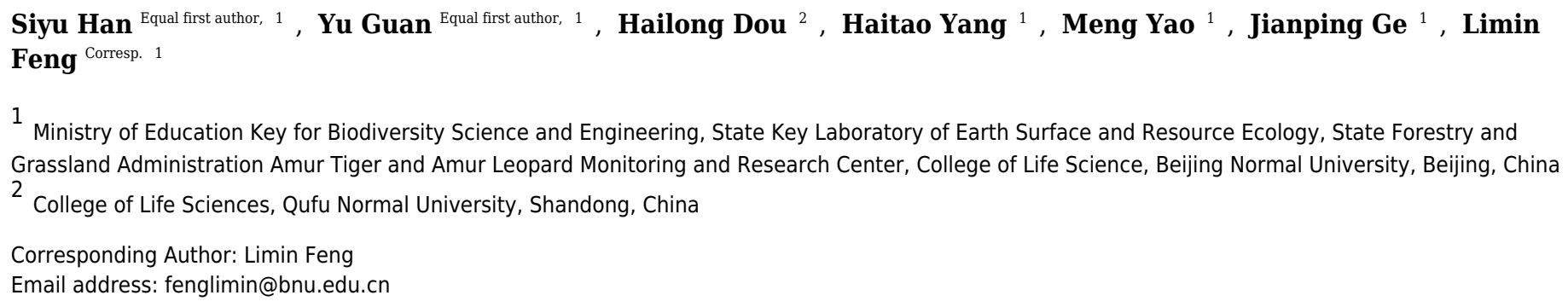

1 Ministry of Education Key for Biodiversity Science and Engineering, State Key Laboratory of Earth Surface and Resource Ecology, State Forestry and Grassland Administration Amur Tiger and Amur Leopard Monitoring and Research Center, College of Life Science, Beijing Normal University, Beijing, China 2 College of Life Sciences, Qufu Normal University, Shandong, China

Corresponding Author: Limin Feng Email address: fenglimin@bnu.edu.cn

The analysis of gut microbiota using fecal samples provides a non-invasive approach to understand the complex interactions between host species and their intestinal bacterial community. However, information on gut microbiota for wild endangered carnivores is scarce. The goal of this study was to describe the gut microbiota of two leopard subspecies, the Amur leopard (Panthera pardus orientalis) and North Chinese leopard (Panthera pardus japonensis). Fecal samples from the Amur leopard $(n=8)$ and North Chinese leopard $(n=13)$ were collected in Northeast China Tiger and Leopard National Park and Shanxi Tieqiaoshan Provincial Nature Reserve, respectively. The gut microbiota of leopards was analyzed via high-throughput sequencing of the V3-V4 region of bacterial $16 S$ rRNA gene using the Life Ion S5TM XL platform. A total of 1,413,825 clean reads representing 4,203 operational taxonomical units (OTUs) were detected. For Amur leopard samples, Firmicutes (78.4\%) was the dominant phylum, followed by Proteobacteria $(9.6 \%)$ and Actinobacteria (7.6\%). And for North Chinese leopard, Firmicutes (68.6\%), Actinobacteria (11.6\%) and Proteobacteria (6.2\%) were the most predominant phyla. Clostridiales was the most diverse bacterial order with 37.9\% for Amur leopard and $45.7 \%$ for North Chinese leopard. Based on the beta-diversity analysis, no significant difference was found in the bacterial community composition between the Amur leopard and North Chinese leopard samples. The current study provides the initial data about the composition and structure of the gut microbiota for wild Amur leopards and North Chinese leopards, and has laid the foundation for further investigations of the health, dietary preferences and physiological regulation of leopards. 
4

\section{Comparison of the fecal microbiota of two free-ranging Chinese subspecies of the leopard} (Panthera pardus) using high-throughput sequencing

Siyu Han $^{1 \dagger}$, Yu Guan ${ }^{1 \dagger}$, Hailong Dou ${ }^{2}$, Haitao Yang ${ }^{1}$, Meng Yao ${ }^{1}$, Jianping Ge ${ }^{1}$, Limin Feng ${ }^{1 *}$

${ }^{1}$ Ministry of Education Key for Biodiversity Science and Engineering, State Key Laboratory of Earth Surface and Resource Ecology, State Forestry and Grassland Administration Amur Tiger and Amur Leopard Monitoring and Research Center, College of Life Sciences, Beijing Normal University, Beijing, 100875, China

${ }^{2}$ College of Life Sciences, Qufu Normal University, Qufu, Shandong, 273165, China

\section{* Corresponding author: Limin Feng}

Address: School of life Science, No. 19, Xin Jie Kou Outer Street, Haidian District, Beijing 100875, P.R.China Telephone: +86-10-58804805

E-mail: fenglimin@bnu.edu.cn

${ }^{\dagger}$ These authors contributed equally to this work. 


\section{Abstract}

24 The analysis of gut microbiota using fecal samples provides a non-invasive approach to understand the complex interactions between host species and their intestinal bacterial community. However, information on gut microbiota for wild endangered carnivores is scarce. The goal of this study was to describe the gut microbiota of two leopard subspecies, the Amur leopard (Panthera pardus orientalis) and North Chinese leopard (Panthera pardus japonensis). Fecal samples from the Amur leopard $(n=8)$ and North Chinese leopard $(n=13)$ were collected in Northeast China Tiger and Leopard National Park and Shanxi Tieqiaoshan Provincial Nature Reserve, respectively. The gut microbiota of leopards was analyzed via high-throughput sequencing of the V3-V4 region of bacterial 16S rRNA gene using the Life Ion S5TM XL platform. A total of $1,413,825$ clean reads representing 4,203 operational taxonomical units (OTUs) were detected. For Amur leopard samples, Firmicutes (78.4\%) was the dominant phylum, followed by Proteobacteria (9.6\%) and Actinobacteria (7.6\%). And for North Chinese leopard, Firmicutes (68.6\%), Actinobacteria (11.6\%) and Proteobacteria (6.2\%) were the most predominant phyla. Clostridiales was the most diverse bacterial order with $37.9 \%$ for Amur leopard and $45.7 \%$ for North Chinese leopard. Based on the beta-diversity analysis, no significant difference was found in the bacterial community composition between the Amur leopard and North Chinese leopard samples. The current study provides the initial data about the composition and structure of the gut microbiota for wild Amur leopards and North Chinese leopards, and has laid the foundation for further investigations of the health, dietary preferences and physiological regulation of leopards. 


\section{Introduction}

45 Leopards (Panthera pardus) are currently the most widely distributed wild felids (Jacobson et al.

46 2016), but they are confronted with worldwide population declines due to illegal poaching, prey

47 depletion, habitat fragmentation, and anthropogenic disturbances (Balme et al. 2009;

48 Hebblewhite et al. 2011; Kissui 2008; Nowell \& Jackson 1996; Packer et al. 2011; Stein et al.

49 2016; Sunquist \& Sunquist 2002). The International Union for the Conservation of Nature

50 (IUCN) recognizes nine subspecies of leopards, including the Amur leopard and the North

51 Chinese leopard (Miththapala et al. 1996; Uphyrkina et al. 2001). The Amur leopard has been

52 classified as critically endangered by IUCN since 1996 (Jackson \& Nowell 2008). Once

53 patrolling from Northeast China to southernmost portions of the Russian Far East and the Korean

54 peninsula (Nowell \& Jackson 1996), the Amur leopard is currently confined to the adjacent

55 habitats in the Jilin and Heilongjiang Provinces in China and southwestern Primorsky Krai in

56 Russia (Feng et al. 2017; Hebblewhite et al. 2011). The North Chinese leopard originally

57 distributed North and Central China but lost as much as $98 \%$ of their historic range. An accurate

58 distribution area and population size still remain unclear due to the lack of empirical

59 investigation (Jacobson et al. 2016). Recently, the Cat Classification Task Force of the IUCN Cat

60 Specialist Group revised the taxonomy of leopards and included the North Chinese leopard in

61 Amur leopard on account of the obscure biogeographical barrier between them (Kitchener et al.

62 2017), although North Chinese leopard was described as the typical subspecies in North China

63 since 1862 (Allen 1938; Gray 1862). Moreover, other evidence based on molecular biology 
64 supporting this classification for the two leopards are scarce, especially in North China.

65 Amur Leopards and North Chinese leopards are large-sized feline species and solitary predators

66 that play pivotal roles in the ecosystems where they occur. Many efforts have been made to

67 uncover their dietary habits, population genetic structure, and individual identification for

68 conservation purposes through non-invasive sampling of feces (Dutta \& Seidensticker 2013;

69 Dutta et al. 2012; Rodgers \& Janečka 2013; Yang et al. 2018). Gut microbial diversity analyses

70 based on leopard fecal samples should also be considered as an important part of conservation

71 efforts. In-depth understanding of relationship between host habitat and microbiota composition

72 may be helpful for conservation efforts because changes in the gut bacterial communities have

73 been shown to affect host metabolism and energy homeostasis (Musso et al. 2010).

74 The gut microbiota composition is an indicator of health condition for endangered wild animals,

75 since habitat degradation may affect host health negatively via diet-associated shifts in the gut

76 microbiota (Amato et al. 2013). Dietary changes caused by human disturbance and habitat

77 degradation likely result in a decrease in microbiota diversity (Barelli et al. 2015). Animal

78 groups from habitat under increased anthropogenic pressure could be distinguished by the

79 comparison of gut bacterial communities (Gomez et al. 2015). Therefore, changes in the gut

80 microbiota species composition of endangered animals might be used as an indicator of habitat

81 degradation and fragmentation (Barelli et al. 2015).

82 Additionally, it has been shown that the detection of pathogenic bacteria is indicative of severe 
83 infectious diseases in endangered species (Zhao et al. 2017), and fecal bacterial composition

84 could alter accordingly with gastrointestinal diseases in animals (Suchodolski et al. 2012).

85 Research has shown that the fecal bacterial species richness was decreased and various bacterial

86 taxa were altered in cats with diarrhea (Suchodolski et al. 2015). Compared with healthy cats,

87 cats with clinical signs of gastrointestinal tract disease had significantly lower amount of microaerophilic bacteria (Johnston et al. 2001).

Residential gut bacteria are also able to serve as a natural barrier against invasive pathogens (Gibson et al. 1995), and to facilitate the function of the immune system (Maynard et al. 2012; Round \& Mazmanian 2009). Specific compositions of the gut microbiota are associated with

92 variations in the host diet, phylogeny, and physiological status (Benson et al. 2010; De et al.

93 2010; Nelson et al. 2013; Sommer \& Bäckhed 2013). Characterization of gut bacterial communities is important in understanding the mechanisms of host-microorganism interactions (Nicholson et al. 2012). Thus, the gut microbiota analysis is fundamental and of paramount importance to the conservation of endangered species. Potentially, the studies of the gut

97 microbiota could be an assistant tool for understanding the phylogenetic relationship of leopard 98 subspecies in the future. Here, we characterized and compared the fecal bacterial communities of the Amur leopard and North Chinese leopard via high-throughput sequencing targeting the V3-V4 hypervariable region of the bacterial 16S rRNA gene, and provide the first benchmark of gut bacterial diversity in Amur and North Chinese leopard that potentially contribute to further conservation research. 
Materials and Methods

\section{Sample collection}

105

106

107

108

109

110

111

112

113

114

115

116

117

118

119

120

121

Opportunistic fecal sampling occurred in the period from December 2016 to March 2017 in the two distribution areas from the leopards. A total of eight (O1-O8) fecal samples of the Amur leopard were obtained from the Northeast China Tiger and Leopard National Park located in the Heilongjiang and Jilin Provinces of China (E129 $\left.05^{\prime}-131^{\circ} 18^{\prime}, \mathrm{N} 42^{\circ} 37^{\prime}-44^{\circ} 10^{\prime}\right)$. This distribution area of the Amur leopard is characterized by a monsoon climate with cold and windy winters, the main vegetation types are mixed broad-leaved forests and secondary Mongolian oak (Quercus mongolica Fisch. ex Ledeb) forest (Tian et al. 2015). A total of 13 fecal samples (J1-

J13) of the North Chinese leopard were collected from Tieqiaoshan Provincial Nature Reserve in Shanxi Province $\left(\mathrm{E} 111^{\circ} 25^{\prime}-114^{\circ} 17^{\prime}, \mathrm{N} 36^{\circ} 39^{\prime}-38^{\circ} 06^{\prime}\right)$. This region is belongs to the warm temperate continental climate with little snow in winter and dry wind in spring, and the vegetation forms are temperate deciduous broad-leaved forests (Zheng et al. 2009). Field experiments were approved by the Forestry Department of Jilin Province, State Forestry Administration and Forestry Department of Shanxi Province.

All fecal samples were collected simultaneously by several groups of our team in different sites.

We designed transects that leopards regularly used based on camera trapping data and sent trained members in field soon after snowfall to collect feces above snow layer where leopard footprint traces were present. Each transect has been revisited more than once at a three day 
122

123

124

125

126

127

128

129

130

131

132

133

134

135

136

137

138

139

140

interval, only newly-excreted feces after previous inspection were collected with the sterile tools.

The low environmental temperature below $0^{\circ} \mathrm{C}$ contributed to the preservation of gut microbes in

the fecal samples. Samples were stored in special ice boxes under $-20^{\circ} \mathrm{C}$ during in-field study and finally stored under $-80^{\circ} \mathrm{C}$ in laboratory for further experiments.

\section{DNA extraction}

Total bacterial genomic DNA was extracted from fecal samples using QIAamp ${ }^{\circledR}$ Stool Mini Kit (Qiagen, Germany) following the manufacturer's protocol. DNA quantity and quality were examined using NanoDrop ${ }^{\text {TM }}$ One (Thermo Fisher Scientific, USA) according to the manufacturer's instruction.

\section{Bacterial 16S rRNA genes amplification and sequencing}

The V3-V4 hypervariable region of the 16S rRNA gene was amplified using primers 341F (5'CCTAYGGGRBGCASCAG-3') and 806R (5'-GGACTACNNGGGTATCTAAT-3'). PCR

amplifications were conducted in a total volume of $50 \mu \mathrm{L}$ mixture containing $6 \mu \mathrm{L}$ of the template DNA, $25 \mu \mathrm{L}$ of $2 \times$ Taq PCR Master Mix $(0.1 \mathrm{U} / \mu \mathrm{L}$; KHBE, China $), 2 \mu \mathrm{L}$ of each primer $(10 \mu \mathrm{M})$ and $15 \mu \mathrm{L} \mathrm{ddH}_{2} \mathrm{O}$. The reaction system was then subjected to 1 cycle of initial denaturation at $95^{\circ} \mathrm{C}$ for $3 \mathrm{~min}$, followed by 25 cycles at $95^{\circ} \mathrm{C}$ for $30 \mathrm{~s}$, annealing at $55^{\circ} \mathrm{C}$ for $30 \mathrm{~s}$ and extension at $72^{\circ} \mathrm{C}$ for $30 \mathrm{~s}$, and a final cycle at $72^{\circ} \mathrm{C}$ for 5 min. Stained with SyBR ${ }^{\circledR}$ Safe DNA Gel Stain (Invitrogen, USA), the PCR products were assessed using electrophoresis in 2\% agarose gels and visualized under UV light. The PCR products were purified using the GeneJET (Thermo Fisher 
141 Scientific, USA).

142 The sequencing libraries were generated using Ion Plus Fragment Library Kit 48 rxns (Thermo

143 Fisher Scientific, USA). DNA concentrations of PCR products were quantified through Qubit

144 and subjected to quality control procedures (Edgar et al. 2011; Haas et al. 2011; Martin 2011a).

145 High-throughput sequencing was performed on a Life Ion S5TM XL (Thermo Fisher Scientific,

146 USA) following the manufacturer's instructions.

147 The data set of our study is available in the Sequencing Read Archive (SRA) on NCBI with

148 accession numbers of SRP149194.

149 Sequence processing and data analysis

150 The original sequencing reads were trimmed using Cutadapt V1.9.1

151 (http://cutadapt.readthedocs.io/en/stable/) (Martin 2011b). Raw reads were obtained after

152 removing barcode and primers. Chimeric sequences were checked and eliminated based on

153 UCHIME Algorithm (http://www.drive5.com/usearch/manual/uchime algo.html) (Edgar et al.

154 2011) and Gold database (http://drive5.com/uchime/uchime download.html) in order to generate

155 clean reads.

156 For all samples, OTUs were generated from clean reads via Uparse v7.0.1001 software

157 (http://drive5.com/uparse/) with a 97\% sequence identity cutoff value (Edgar 2013). Using

158 Mothur (Schloss et al. 2009), representative sequences of the OTUs which chosen by the highest 
159

160

161

162

163

164

165

166

167

168

169

170

171

172

173

174

175

176

177

frequency of occurrence, were annotated against the SILVA SSUrRNA database

(http://www.arb-silva.de/) (Quast et al. 2013; Schloss et al. 2009; Wang et al. 2007) and aligned

by MUSCLE (Version 3.8.31) (Edgar 2004) to construct the phylogenetic relationship between different OTUs.

Series of alpha-diversity indices including observed species, Shannon, Simpson, Chao1, ACE, and Goods coverage were calculated and analyzed in QIIME (Version 1.9.1) (Caporaso et al. 2010). The rarefaction curves and rank abundance curves were constructed in $\mathrm{R}$ (Version 2.15.3). We applied Wilcoxon rank-sum test to identify discrepancies of gut bacterial diversities between the Amur leopard and North Chinese leopard for each index of alpha-diversity.

Using QIIME pipeline (Version 1.9.1), beta-diversity was assessed by calculation of Unifrac distances and subsequently visualized by principal component analysis (PCoA). Phylogenetic trees were also built using UPGMA (unweighted pair group method with arithmetic mean). The principal component analysis (PCA), principal co-ordinate analysis (PCoA) and non-metric multidimensional scaling (NMDS) were calculated using $\mathrm{R}$ (Version 2.15.3) so as to evaluate the similarity and discrepancies of bacterial communities among fecal samples based on weighted and unweighted distance matrix. The Analysis of Similarities (ANOSIM) was also used to testify whether there was a significant difference between two groups (Clarke 1993). Beta-diversity was then subjected to Wilcoxon rank-sum test. To detect differentially species between two groups, metastats was used in R (Version 2.15.3) (White et al. 2009). 
178

179

180

181

182

183

\section{Results}

\section{Overall sequencing data}

A total of 1,514,233 raw reads were yielded after high-throughput sequencing of all samples.

The data sets were then subjected to quality control procedures which resulted in $1,413,825$ clean reads for the 21 samples analyzed. The total number of OTUs was 4,203 at a threshold of 97\% sequence identity for all samples.

Alpha-diversity indices including Observed species, Shannon, Simpson, Chao1, ACE and Goods coverage are shown in Table 1. The rarefaction curves showed a pattern of plateau formation

(Fig. 1A), indicating that the microbial diversity present in each sample was sufficiently quantified at this sequencing depth. We also analyzed the rank abundance curves to evaluate the abundance and distribution of bacteria taxa (Fig. 1B).

\section{Bacteria composition and relative abundance}

Overall, we identified 28 phyla, 55 classes, 88 orders, 167 families and 344 genera of bacteria in the gut microbiota community from 21 fecal samples of leopards.

For the Amur leopard, Firmicutes was the predominant phylum (78.4\%) (Fig. 2). Proteobacteria (9.6\%), Actinobacteria (7.6\%), Bacteroidetes (2.6\%) and Fusobacteria (1.7\%) contributed also to the total composition. At the family level, Planococcaceae (30.1\%), Clostridiaceae 1 (17.2\%) and Peptostreptococcaceae (14.5\%) were the top 3 dominant families. At the genus level, 
196

197

198

199

200

201

202

203

204

205

206

207

208

209

210

211

212

213

214

Sporosarcina was predominant with an abundance of $22.8 \%$, followed by Clostridium sensu stricto $1(17.1 \%)$ and Peptoclostridium (10.2\%).

For the North Chinese leopard, Firmicutes (68.6\%) was the most predominant phylum (Fig. 2), followed by Actinobacteria (11.6\%), Proteobacteria (6.2\%), Bacteroidetes $(6.0 \%)$ and Fusobacteria (6.4\%). And Clostridiaceae_l (19.5\%), Planococcaceae (16.2\%) and Lachnospiraceae (12.5\%) were the three most predominant families. At the genus level, Clostridium sensu stricto 1 (19.4\%), Sporosarcina (9.5\%) and Peptoclostridium (6.1\%) constituted the top 3 genera.

The clustered heatmap showed (Fig. 3A) that the gut bacterial distribution of the Amur leopard and North Chinese leopard were relatively scattered. The unweighted pair-group method with arithmetic means (UPGMA) (Fig. 3B) that display the similarities between sample groups showed a similar result with the clustered heatmap.

\section{Differences in community composition}

The boxplots of alpha diversity were shown in Fig. 4A. Observed species and Shannon diversity indices were tested for the significance of discrepancies between the two sample groups ( $p=$ 0.4466 and 0.2103 , respectively). The beta-diversity indices were presented in Fig. 4B ( $p=$ 0.441 land 0.0029 , respectively), illustrating the discrepancies of gut bacterial communities between different groups. The Analysis of Similarities (ANOSIM) showed the significance level between different groups $(\mathrm{R}=0.02, p=0.335)($ Fig. $\mathrm{S} 1)$. The heatmap of beta-diversity indices 

were also plotted in Fig. S2.

216 Non-metric multidimensional scaling (NMDS) displayed separation in gut microbiota

217 composition of the Amur and North Chinese leopard, and the stress value less than 0.2 could

218 show the discrepancy between samples was 0.110 (Fig. 5A). The PCA plot (Fig. 5B) revealed

219 that the samples from the two subspecies are basically clustered together. The main components

220 of the gut microbiota of the Amur leopard and North Chinese leopard were similar with two

221 exceptional samples from the North Chinese leopard. According to the PCoA analysis (Fig. 5C,

222 D), the fecal bacterial communities of Amur leopard and North Chinese leopard were relatively

223 scattered in every groups. Overall, no significant differences were found between the two sample

224 species according to the results of PCoA, PCA and NMDS.

\section{Discussion}

226 With the rapid development of high-throughput sequencing technology, there are mounting

227 studies focusing on the analysis of gut microbiota in different vertebrates. Amur leopards and

228 North Chinese leopards are endangered flagship species facing severe survival predicament

229 result from prey depletion, habitat fragmentation, and anthropogenic disturbances. However,

230 research effort on free-ranging leopards in China, especially for North Chinese leopards are

231 neglected (Jacobson et al. 2016). In this study, we characterized and compared the gut

232 microbiota of Amur leopards and North Chinese leopards for the first time using high-throughput

233 sequencing technology. The characterization of their gut microbiota might be able to provide

useful information for potential research and help us evaluate the healthy condition of wild 
leopards in their natural habitat.

236 Five major bacterial phyla were observed including Firmicutes, Proteobacteria, Actinobacteria,

237 Bacteroidetes and Fusobacteria both in the Amur and North Chinese leopard samples, which is

238 in accordance with the vertebrate gut microbial diversity described by many other studies (Deng

239 \& Swanson 2014; Ley et al. 2008; Ritchie et al. 2008). Fecal samples of healthy cats are featured

240 with similar phylum composition with slightly different proportions (Barry et al. 2012). Based on

241 our analysis, no significant difference was found in the relative abundance of these five phyla

242 between the samples from the Amur leopard and North Chinese leopard.

243 Firmicutes was the most predominant phylum in both the Amur leopard and North Chinese

244 leopard and showed no significant difference between two groups $(p=0.28)$. Previous researches

245 have reported that Firmicutes is the most dominant phylum in feces of animals (Garcia-Mazcorro

246 et al. 2012; Guan et al. 2017; Ritchie et al. 2010) and humans (Arumugam et al. 2011). Same

247 tendency was also found in feline species in the wild such as leopard cats (Prionailurus

248 bengalensis) (An et al. 2017) and snow leopards (Panthera uncia) (Zhang et al. 2015). Some

249 studies reported that the body fat storage influences the gut bacterial composition in mice (Ley et

250 al. 2005) and humans (Ley et al. 2006). A significantly greater proportion of Firmicutes and a

251 significant reduction of Bacteroidetes were observed in obese animals than in lean controls

252 (Turnbaugh et al. 2006). The tendency of an increase in Firmicutes and a decrease in

253 Bacteroidetes was associated with switching to the high fat diet (Hildebrandt et al. 2009;

254 Tremaroli \& Bäckhed 2012). We detected that the proportion of Firmicutes in Amur leopards 
255 was relatively greater than in North Chinese leopards, and the proportion of Bacteroidetes in

256 Amur leopards was relatively lower which indicated that the weight of Amur leopard should be

257 more heavier. This might relate to the greater body fat storage of Amur leopards compare with

258 North Chinese leopards, since Amur leopards have larger body size and store more fat to

259 withstand severe cold in further north habitat (Wang et al. 2017). Unfortunately, the detail

260 information about wild North Chinese leopard is comparatively scarce.

261 Within the phylum Firmicutes, Zhang et al. (2015) found that Lachnospiraceae was the most

262 diverse family in the feces of snow leopards, which is consistent with a previous report in wolves

263 (Zhang \& Chen 2010). In our results, however, the most diverse family was Clostridiaceae 1

264 (19.5\% in North Chinese leopard, 17.2\% in Amur leopard) within the order Clostridiales, and

265 Lachnospiraceae constituted a relatively small proportion in our sample set compared to snow

266 leopards and wolves. Lachnospiraceae was found in both human and mammal gut microbiota

267 that relates to some diseases like colon cancer (Meehan \& Beiko 2014), nonalcoholic fatty liver

268 disease (NAFLD) (Shen et al. 2017) and diabetes (Kameyama \& Itoh 2014). However, without

269 sufficient support based on other health monitoring methods including blood or apparatus test,

270 the proportion of Lachnospiraceae in the gut microbiota could only be a simple referential

271 marker that reflects health condition for wild animals.

272 Our results also indicate that Clostridium sensu stricto 1 was a predominant genus in the gut

273 microbiota of leopards. And Clostridium perfringens was a common bacterial species for both

274 the Amur and North Chinese leopard. Lubbs et al. (2009) reported that the gut microbiota of 
275 domestic cats is affected by the protein concentration in diets, particularly, Clostridium

276 populations increased as more protein was digested. The presence of $C$. perfringens was

277 positively associated with protein intake in grizzly bears (Schwab et al. 2011) and cheetahs

278 (Becker et al. 2014). To our knowledge, leopards are highly carnivorous and consume mostly

279 protein in their daily diet (Martins et al. 2011). We speculate that the high proportions of

280 Clostridium populations might reflect the high-protein diet of leopards in our study. Interestingly,

C. perfringens might be potential pathogenic bacteria that cause diarrhea in dogs (Canis lupus

familiaris) and cats (Felis catus) (Suchodolski 2011). However, C. perfringens was also detected

283 in the clinically healthy dogs and house cats (Handl et al. 2011; Queen et al. 2012). C.

perfringens should probably be considered as a common commensal in the intestine of healthy

285 feline (Becker et al. 2014).

The relationship between gut microbiota and gastrointestinal diseases including inflammatory

bowel disease (IBD), chronic enteropathies (CE), and acute diarrhea in Carnivora are welldocumented (Suchodolski 2016). For examples, there are increases in the proportions of bacterial genera belonging to Proteobacteria and decreases in Fusobacteria, Bacteroidetes, and

Firmicutes in canine IBD (Yasushi et al. 2015). And an increase of Enterobacteriaceae along with decreased proportions of Bacteroidetes, Faecalibacterium spp. and Turicibacter spp. were observed in cats with chronic diarrhea (Suchodolski et al. 2015). It indicates that some gut microbiota dysbiosis, which caused by disease processes, can be identified in fecal samples

294 (Suchodolski 2016). 
295

296

297

298

299

300

301

302

303

304

305

306

307

Proteobacteria was another phylum in the gut microbiota of the leopards and was not significantly different between two subspecies $(p=0.56)$. Proteobacteria was also detected in other feline gut microbiota analysis based on different methods (Ozaki et al. 2009; Ritchie et al. 2008). As the most predominant phylum in giant panda, Proteobacteria play crucial role in degrading lignin, which is the main ingredient of bamboo (Fang et al. 2012), and in catabolizing complicated compounds in fodder (Evans et al. 2011). Proteobacteria was the most predominant phylum in the gut microbiota of dogs in the obese groups while in the lean groups was Firmicutes (Park et al. 2015), and the proportion of Proteobacteria was related with inflammatory bowel disorder (IBD) and Clostridium difficile infection (Chang et al. 2008;

Packey \& Sartor 2009) as well. For many large mammals in the wild, noninvasive sampling such as collecting feces or hairs are relative feasible and effective method to obtain information, but the real-time living situation and health condition of some wild species are still unclear, as well as the definite function of different bacteria in host health.

The phylum Actinobacteria also contributed to the gut microbiota of the leopards and its proportion was not significantly different between the two subspecies $(p=0.45)$. It was identified to be the most predominant phylum in snow leopards (Zhang et al. 2015). In contrast, Wu et al. (2017) reported that Actinobacteria constituted $0.53 \%$ of all gut bacteria in wolves (Canis lupus). Handl et al. (2011) found that Actinobacteria constituted 7.3\% of all bacterial sequences in house cats, but was at a low abundance in dogs (1.8\%). This result in regard to dogs was in line with an analysis using 454 pyrosequencing (Middelbos et al. 2010). There might be a 
315 different tendency in the abundance of Actinobacteria between feline and canine species, or

316 perhaps the abundance of Actinobacteria in the mammalian gut is currently biased, because

317 sequencing methodology without prior $\% \mathrm{G}+\mathrm{C}$ profiling might underestimate the proportion of

318 high G+C bacteria including Actinobacteria (Harri et al. 2009).

319 Bacteroidetes was another contributive phylum in the gut microbiota of the leopards and showed

320 no significant difference between groups $(p=0.37)$. Bacteroidetes ranks over Firmicutes as the

321 most predominant phylum in some cases, as shown in domestic cats and dholes (Cuon alpinus)

322 (Jacobson et al. 2016; Tun et al. 2012). The relative abundance of Bacteroidetes varied

323 significantly in different studies (Handl et al. 2011; Ritchie et al. 2010). Within Bacteroidetes,

324 the genus of Bacteroides contributed 1.1\% and 3.2\% to the gut microbiota of the Amur leopard

325 and North Chinese leopard, respectively. Bacteroides species were reported that took part closely

326 in the breakdown of complex molecules, such as polysaccharides, also the biotransformation of

327 bile acids (Lan et al. 2006; Reeves et al. 1997). Additionally, this crucial genus could inhibit

328 some pathogenic micro-organisms (like Escherichia coli, Klebsiella pneumonia) with other

329 anaerobic bacteria, which beneficial to host (Hentges 1983; Van der Waaij et al. 1971). Although

330 the presence of Bacteroides in the gut microbiota might be beneficial to the health condition of

331 leopard to some extent, more feces samples should be collected for further investigation with

332 camera trap data and identified individual in the nature reserves to prove the above inferences.

333 With regard to other phylum Fusobacteria detected in the feces of leopards, no significant

334 difference was found between samples from the two subspecies $(p=0.21)$. Research based on 
335

336

337

338

339

pyrosequencing suggested that Fusobacteria were less abundant in domestic cats than in domestic dogs (Garciamazcorro et al. 2011). This tendency might be analogous to the relationship of gut microbiota observed in raccoon dogs (Nyctereutes procyonoides) and leopard cats (An et al. 2017).

In summary, although the proportions of the five predominant bacterial phyla are slightly different among the gut bacteria of the Amur leopard and North Chinese leopard, no significant difference was found in phylum composition between the two subspecies. Previous work has shown that the gut microbial community structure of species can vary in different environments (Clayton et al. 2016), and respond to dietary alterations, including the amount and type of dietary fiber or other bioactive food components (Turnbaugh et al. 2008). The potential prey for the Amur leopard includes Siberian roe deer (Capreolus pygarus), sika deer (Cervus nippon), wild boar (Sus scrofa) and Badger (Meles meles) in the Northeast China Tiger and Leopard National Park (Yang et al. 2018). However, sika deer is not available for North Chinese leopard in Tieqiaoshan Provincial Nature Reserve (Wu et al. 2004), which indicates that in addition to the relative different dietary components and living environment, there are other influence factors play crucial roles for the gut microbiota of wild leopard. We speculate that genetic factors might be responsible for the same tendency in gut microbiota composition, after all the classification of this two subspecies leopard is still controversial around the world due to the lack of efficient evidence in molecular biology. At the genus level, however, the bacterial composition for each fecal sample is individualized. Due to the principles of noninvasive sampling, there may be some 
355

356

357

358

359

360

361

362

363

364

365

366

367

368

369

370

371

372

373

variables that cannot be measured easily, such as age, sex, real-time healthy condition or dietary shift of wild leopards, which account for the individualized bacterial microbiota at genus level.

More fecal or intestinal samples from wild leopards are required for in-depth analysis of the gut bacterial community. The metabolic pathway of bacterial species should also be taken into account to provide a more comprehensive insight into the functional repertoire of the leopard gut microbiota. Although the implications of changes in gut microbiome for human and other species have been showed in many studies, the implications for wild animal conservation are still limited (Bahrndorff et al. 2016). Other studies also suggested that microbiome and fitness of host could be influenced by habitat fragmentation (Amato et al. 2013; Cheng et al. 2015). For instance, for these rare endangered animals, captivity and reintroduction into the wild are the common methods for their conservation. The gut microbiome of captive animals could be established with excepted nutritional conditions by special diets as the wild individual, and reintroduction would have relative high success rate when captive animals facing vary uncertain environment. It is necessary that figure out the relationship between habitat fragmentation and gut microbiome, as well as the performance of diverse gut microbiome under different conditions. In general, our study presents the characterization and comparison of the gut microbiota for wild leopards, which might be able to provide a theoretical reference both for free-ranging leopards and ex-situ conservation.

\section{Conclusions}

374 We first reported and compared the basic composition and structure of the fecal microbiota 
375 between wild Amur leopard and North Chinse leopard. We observed that Firmicutes,

376 Proteobacteria and Actinobacteria were the three most predominant phyla in the gut microbiota

377 of both Amur leopard and North Chinese leopard. Although their living environment and diet are

378 relatively diverse, no significant difference was found in the main composition and structure of

379 the gut microbiota at phylum level. We speculate that the same structure of fecal microbiota

380 might result from genetic factors of leopard, the small sample size or too much variability within

381 the groups. In order to understand the gut microbial ecology of Amur and North Chinese

382 leopards, future research should focus on within-individual variation in microbial community

383 structure, and how gut microbiome structure changes with seasonal shifts in temperature and diet.

384 Furthermore, other methods including functional metagenomics of the gut microbiome, and

385 whole genome sequencing of leopards, integrated with behavioural data from infrared camera

386 traps in the field will be beneficial for leopard conservation.

\section{Acknowledgments}

388 We sincerely thank Tonggang Chen, Shuyun Peng, Zhanzheng Sun, Chunze Tan, Dazhao Song,

Shaoping Wan, Shiming Cui, Qiaowen Huang, and Yuelong Chen for field assistance. 
394

\section{Reference}

Allen GM. 1938. The mammals of China and Mongolia. American Museum of Natural History 11:1-620.

Amato KR, Yeoman CJ, Kent A, Righini N, Carbonero F, Estrada A, Gaskins HR, Stumpf RM, Yildirim S, and Torralba M. 2013. Habitat degradation impacts black howler monkey (Alouatta pigra) gastrointestinal microbiomes. The ISME journal 7:1344.

An C, Okamoto Y, Xu S, Eo KY, Kimura J, and Yamamoto N. 2017. Comparison of fecal microbiota of three captive carnivore species inhabiting Korea. Journal of Veterinary Medical Science 79:542-546.

Arumugam M, Raes J, Pelletier E, Paslier DL, Yamada T, Mende DR, Fernandes GR, Tap J, Bruls T, and Batto JM. 2011. Enterotypes of the human gut microbiome. Nature 473:174.

Bahrndorff S, Alemu T, Alemneh T, and Lund Nielsen J. 2016. The microbiome of animals: implications for conservation biology. International journal of genomics 2016.

Balme GA, Slotow R, and Hunter LT. 2009. Impact of conservation interventions on the dynamics and persistence of a persecuted leopard (Panthera pardus) population. Biological Conservation 142:2681-2690.

Barelli C, Albanese D, Donati C, Pindo M, Dallago C, Rovero F, Cavalieri D, Tuohy KM, Hauffe HC, and De Filippo C. 2015. Habitat fragmentation is associated to gut microbiota diversity of an endangered primate: implications for conservation. Scientific Reports 5:14862.

Barry KA, Middelbos IS, Vester Boler BM, Dowd SE, Suchodolski JS, Henrissat B, Coutinho PM, White BA, Jr FG, and Swanson KS. 2012. Effects of dietary fiber on the feline gastrointestinal metagenome. Journal of Proteome Research 11:5924-5933.

Becker AA, Hesta M, Hollants J, Janssens GP, and Huys G. 2014. Phylogenetic analysis of faecal microbiota from captive cheetahs reveals underrepresentation of Bacteroidetes and Bifidobacteriaceae. BMC microbiology 14:43.

Benson AK, Kelly SA, Legge R, Ma F, Low SJ, Kim J, Zhang M, Oh PL, Nehrenberg D, and Hua K. 2010. Individuality in gut microbiota composition is a complex polygenic trait shaped by multiple environmental and host genetic factors. Proceedings of the National Academy of Sciences of the United States of America 107:18933.

Caporaso JG, Kuczynski J, Stombaugh J, Bittinger K, Bushman FD, Costello EK, Fierer N, Peña AG, Goodrich JK, and Gordon JI. 2010. QIIME allows analysis of high-throughput community sequencing data. Nat Methods:335336.

Chang JY, Antonopoulos DA, Kalra A, Tonelli A, Khalife WT, Schmidt TM, and Young VB. 2008. Decreased diversity of the fecal microbiome in recurrent Clostridium difficile-associated diarrhea. The Journal of infectious diseases 197:435-438.

Cheng Y, Fox S, Pemberton D, Hogg C, Papenfuss AT, and Belov K. 2015. The Tasmanian devil microbiomeimplications for conservation and management. Microbiome 3:76.

Clarke KR. 1993. Non-parametric multivariate analyses of changes in community structure. Austral Ecology 18:117143.

Clayton JB, Vangay P, Huang H, Ward T, Hillmann BM, Al-Ghalith GA, Travis DA, Long HT, Tuan BV, Minh VV, Cabana F, Nadler T, Toddes B, Murphy T, Glander KE, Johnson TJ, and Knights D. 2016. Captivity 
432

433

434

435

436

437

438

439

440

441

442

443

444

445

446

447

448

449

450

451

452

453

454

455

456

457

458

459

460

461

462

463

464

465

466

467

468

469

470

471

472

humanizes the primate microbiome. Proceedings of the National Academy of Sciences 113:10376-10381. 10.1073/pnas.1521835113

De FC, Cavalieri D, Di PM, Ramazzotti M, Poullet JB, Massart S, Collini S, Pieraccini G, and Lionetti P. 2010. Impact of diet in shaping gut microbiota revealed by a comparative study in children from Europe and rural Africa. Proceedings of the National Academy of Sciences of the United States of America 107:14691-14696.

Deng P, and Swanson KS. 2014. Gut microbiota of humans, dogs and cats: current knowledge and future opportunities and challenges. British Journal of Nutrition 113 Suppl:S6.

Dutta T, and Seidensticker J. 2013. Fine-scale population genetic structure in a wide-ranging carnivore, the leopard (Panthera pardus fusca) in central India. Diversity \& Distributions 19:760-771.

Dutta T, Sharma S, Maldonado JE, Wood TC, and Seidensticker J. 2012. A reliable method for individual identification and gender determination of wild leopards (Panthera pardus fusca) using non-invasive samples. Conservation Genetics Resources 4:665-667.

Edgar RC. 2004. MUSCLE: multiple sequence alignment with high accuracy and high throughput. Nucleic Acids Research 32:1792-1797.

Edgar RC. 2013. UPARSE: highly accurate OTU sequences from microbial amplicon reads. Nature Methods 10:996998.

Edgar RC, Haas BJ, Clemente JC, Quince C, and Knight R. 2011. UCHIME improves sensitivity and speed of chimera detection. Bioinformatics 27:2194.

Evans NJ, Brown JM, Murray RD, Brian G, Birtles RJ, C Anthony H, and Carter SD. 2011. Characterization of novel bovine gastrointestinal tract Treponema isolates and comparison with bovine digital dermatitis treponemes. Applied and Environmental Microbiolgy 77:138-147.

Fang W, Fang Z, Zhou P, Chang F, Hong Y, Zhang X, Peng H, and Xiao Y. 2012. Evidence for Lignin Oxidation by the Giant Panda Fecal Microbiome. PLOS ONE 7:e50312. 10.1371/journal.pone.0050312

Feng L, Shevtsova E, Vitkalova A, Matyukhina D, Miquelle D, Aramilev V, Wang T, Mu P, Xu R, and Ge J. 2017. Collaboration brings hope for the last Amur leopards. Cat News 65:20.

Garcia-Mazcorro JF, Dowd SE, Jeffrey P, Steiner JM, and Suchodolski JS. 2012. Abundance and short-term temporal variability of fecal microbiota in healthy dogs. Microbiologyopen 1:340-347.

Garciamazcorro JF, Lanerie DJ, Dowd SE, Paddock CG, Grützner N, Steiner JM, Ivanek R, and Suchodolski JS. 2011. Effect of a multi-species synbiotic formulation on fecal bacterial microbiota of healthy cats and dogs as evaluated by pyrosequencing. Fems Microbiology Ecology 78:542-554.

Gibson GR, Probert HM, Loo JV, Rastall RA, and Roberfroid MB. 1995. Dietary modulation of the human colonic microbiota: updating the concept of prebiotics. Journal of Nutrition 17:1401-1412.

Gomez A, Petrzelkova K, Yeoman CJ, Vlckova K, Koppova I, Carbonero F, Ulanov A, Modry D, Todd A, and Torralba M. 2015. Gut microbiome composition and metabolomic profiles of wild western lowland gorillas (Gorilla gorilla gorilla) reflect host ecology. Molecular Ecology 24:2551-2565.

Gray JE. 1862. Description of some New Species of Mammalia. Proceedings of the Zoological Society of London. $\mathrm{p}$ 261-263.

Guan Y, Yang H, Han S, Feng L, Wang T, and Ge J. 2017. Comparison of the gut microbiota composition between wild and captive sika deer (Cervus nippon hortulorum) from feces by high-throughput sequencing. Amb Express 7:212.

Haas BJ, Gevers D, Earl AM, Feldgarden M, Ward DV, Giannoukos G, Ciulla D, Tabbaa D, Highlander SK, and 
Sodergren E. 2011. Chimeric 16S rRNA sequence formation and detection in Sanger and 454pyrosequenced PCR amplicons. Genome Research 21:494.

Handl S, Dowd SE, Garciamazcorro JF, Steiner JM, and Suchodolski JS. 2011. Massive parallel 16S rRNA gene pyrosequencing reveals highly diverse fecal bacterial and fungal communities in healthy dogs and cats. Fems Microbiology Ecology 76:301-310.

Harri M, Jukka C, Lars P, Anna K, Lotta KK, Jarno T, and Airi P. 2009. Sequence analysis of percent G+C fraction libraries of human faecal bacterial DNA reveals a high number of Actinobacteria. BMC microbiology 9:68.

Hebblewhite M, Miquelle DG, Murzin AA, Aramilev VV, and Pikunov DG. 2011. Predicting potential habitat and population size for reintroduction of the Far Eastern leopards in the Russian Far East. Biological Conservation 144:2403-2413.

Hentges D. 1983. Role of the intestinal flora in host defense against infection. Human intestinal microflora in health and disease:311-331.

Hildebrandt MA, Hoffmann C, Sherrillmix SA, Keilbaugh SA, Hamady M, Chen YY, Knight R, Ahima RS, Bushman F, and Wu GD. 2009. High-fat diet determines the composition of the murine gut microbiome independently of obesity. Gastroenterology 137:1716-1724.

Jackson P, and Nowell K. 2008. Panthera pardus ssp. orientalis. The IUCN Red List of Threatened Species 2008. RLTS T15957A5333757 en.

Jacobson AP, Gerngross P, Jr LJ, Schoonover RF, Anco C, Breitenmoser-Würsten C, Durant SM, Farhadinia MS, Henschel P, and Kamler JF. 2016. Leopard (Panthera pardus) status, distribution, and the research efforts across its range. Peerj 4:e1974.

Johnston KL, Swift NC, Forster-van Hijfte M, Rutgers HC, Lamport A, Ballàvre O, and Batt RM. 2001. Comparison of the bacterial flora of the duodenum in healthy cats and cats with signs of gastrointestinal tract disease. Journal of the American Veterinary Medical Association 218:48-51.

Kameyama K, and Itoh K. 2014. Intestinal colonization by a Lachnospiraceae bacterium contributes to the development of diabetes in obese mice. Microbes and environments 29:427-430.

Kissui BM. 2008. Livestock predation by lions, leopards, spotted hyenas, and their vulnerability to retaliatory killing in the Maasai steppe, Tanzania. Animal Conservation 11:422-432.

Kitchener AC, Breitenmoser C, Eizirik E, Gentry A, Werdelin L, Wilting A, Yamaguchi N, Abramov AV, Christiansen P, Driscoll CA, Duckworth W, Johnson WE, Luo S, Meijaard E, Donoghue PO, Sanderson J, Seymour K, Bruford MW, Groves C, Hoffmann M, Nowell K, Timmons Z, and Tobe SS. 2017. A revised taxonomy of the Felidae. Cat News 11:1-80.

Lan PT, Sakamoto M, Sakata S, and Benno Y. 2006. Bacteroides barnesiae sp. nov., Bacteroides salanitronis sp. nov. and Bacteroides gallinarum sp. nov., isolated from chicken caecum. International Journal of Systematic \& Evolutionary Microbiology 56:2853-2859.

Ley RE, Bäckhed F, Turnbaugh P, Lozupone CA, Knight RD, and Gordon JI. 2005. Obesity alters gut microbial ecology. Proceedings of the National Academy of Sciences 102:11070-11075.

Ley RE, Hamady M, Lozupone C, Turnbaugh PJ, Ramey RR, Bircher JS, Schlegel ML, Tucker TA, Schrenzel MD, and Knight R. 2008. Evolution of mammals and their gut microbes. Science 320:1647-1651.

Ley RE, Peterson DA, and Gordon JI. 2006. Ecological and evolutionary forces shaping microbial diversity in the human intestine. Cell 124:837-848.

Lubbs DC, Vester BM, Fastinger ND, and Swanson KS. 2009. Dietary protein concentration affects intestinal 
514

515

516

517

518

519

520

521

522

523

524

525

526

527

528

529

530

531

532

533

534

535

536

537

538

539

540

541

542

543

544

545

546

547

548

549

550

551

552

553

554

microbiota of adult cats: a study using DGGE and qPCR to evaluate differences in microbial populations in the feline gastrointestinal tract. J Anim Physiol Anim Nutr 93:113-121.

Martin M. 2011a. Cutadapt removes adapter sequences from high-throughput sequencing reads. EMBnet journal 17:pp. 10-12.

Martin M. 2011b. Cutadapt removes adapter sequences from high-throughput sequencing reads. Embnet Journal 17.

Martins Q, Horsnell W, Titus W, Rautenbach T, and Harris S. 2011. Diet determination of the Cape Mountain leopards using global positioning system location clusters and scat analysis. Journal of Zoology 283:81-87.

Maynard CL, Elson CO, Hatton RD, and Weaver CT. 2012. Reciprocal interactions of the intestinal microbiota and immune system. Nature 489:231-241.

Meehan CJ, and Beiko RG. 2014. A phylogenomic view of ecological specialization in the Lachnospiraceae, a family of digestive tract-associated bacteria. Genome biology and evolution 6:703-713.

Middelbos IS, Boler BMV, Qu A, White BA, Swanson KS, and Fahey GC. 2010. Phylogenetic characterization of fecal microbial communities of dogs fed diets with or without supplemental dietary fibery using 454 pyrosequencing. PLOS ONE 5:e9768.

Miththapala S, Seidensticker J, and O'Brien SJ. 1996. Phylogeographic subspecies recognition in leopards (Panthera pardus): molecular genetic variation. Conservation Biology 10:1115-1132.

Musso G, Gambino R, and Cassader M. 2010. Gut microbiota as a regulator of energy homeostasis and ectopic fat deposition: mechanisms and implications for metabolic disorders. Current Opinion in Lipidology 21:76.

Nelson TM, Rogers TL, Carlini AR, and Brown MV. 2013. Diet and phylogeny shape the gut microbiota of Antarctic seals: a comparison of wild and captive animals. Environmental Microbiology 15:1132-1145.

Nicholson JK, Holmes E, Kinross J, Burcelin R, Gibson G, Jia W, and Pettersson S. 2012. Host-gut microbiota metabolic interactions. Science 336:1262-1267.

Nowell K, and Jackson P. 1996. Status survey and conservation action plan: wild cats. Biological Conservation 83:324.

Ozaki Y, Diwan AR, Mcbride WD, and Melnick JL. 2009. Characterization and quantification of feline fecal microbiota using cpn60 sequence-based methods and investigation of animal-to-animal variation in microbial population structure. Veterinary Microbiology 137:120-128.

Packer C, Brink H, Kissui BM, Maliti H, Kushnir H, and Caro T. 2011. Effects of trophy hunting on lion and leopard populations in Tanzania. Conservation Biology 25:142-153.

Packey CD, and Sartor RB. 2009. Commensal bacteria, traditional and opportunistic pathogens, dysbiosis and bacterial killing in inflammatory bowel diseases. Current opinion in infectious diseases 22:292.

Park HJ, Lee SE, Kim HB, Isaacson R, Seo KW, and Song KH. 2015. Association of obesity with serum leptin, adiponectin, and serotonin and gut microflora in beagle dogs. Journal of Veterinary Internal Medicine 29:43-50.

Quast C, Pruesse E, Yilmaz P, Gerken J, Schweer T, Yarza P, Peplies J, and Glöckner FO. 2013. The SILVA ribosomal RNA gene database project: improved data processing and web-based tools. Nucleic Acids Research 41:590-596.

Queen EV, Marks SL, and Farver TB. 2012. Prevalence of Selected Bacterial and Parasitic Agents in Feces from Diarrheic and Healthy Control Cats from Northern California. Journal of Veterinary Internal Medicine 26:54-60.

PeerJ reviewing PDF | (2018:08:30233:3:0:NEW 20 Feb 2019) 
555

556

557

558

559

560

561

562

563

564

565

566

567

568

569

570

571

572

573

574

575

576

577

578

579

580

581

582

583

584

585

586

587

588

589

590

591

592

593

594

595

Reeves AR, Wang GR, and Salyers AA. 1997. Characterization of four outer membrane proteins that play a role in utilization of starch by Bacteroides thetaiotaomicron. Journal of Bacteriology 179:643.

Ritchie LE, Burke KF, Garcia-Mazcorro JF, Steiner JM, and Suchodolski JS. 2010. Characterization of fecal microbiota in cats using universal $16 \mathrm{~S}$ rRNA gene and group-specific primers for Lactobacillus and Bifidobacterium spp. Veterinary Microbiology 144:140-146.

Ritchie LE, Steiner JM, and Suchodolski JS. 2008. Assessment of microbial diversity along the feline intestinal tract using 16S rRNA gene analysis. Fems Microbiology Ecology 66:590.

Rodgers TW, and Janečka JE. 2013. Applications and techniques for non-invasive faecal genetics research in felid conservation. European Journal of Wildlife Research 59:1-16.

Round JL, and Mazmanian SK. 2009. The gut microbiota shapes intestinal immune responses during health and disease. Nature Reviews Immunology 9:313-323.

Schloss PD, Westcott SL, Ryabin T, Hall JR, Hartmann M, Hollister EB, Lesniewski RA, Oakley BB, Parks DH, and Robinson CJ. 2009. Introducing mothur: open-source, platform-independent, community-supported software for describing and domparing microbial cmmunities. Applied \& Environmental Microbiology 75:7537.

Schwab C, Cristescu B, Northrup JM, Stenhouse GB, and Gänzle M. 2011. Diet and environment shape fecal bacterial microbiota composition and enteric pathogen load of grizzly bears. PLOS ONE 6:e27905.

Shen F, Zheng R, Sun X, Ding W, Wang X, and Fan J. 2017. Gut microbiota dysbiosis in patients with non-alcoholic fatty liver disease. Hepatobiliary \& Pancreatic Diseases International 16:375-381.

Sommer F, and Bäckhed F. 2013. The gut microbiota- masters of host development and physiology. Nature Reviews Microbiology 11:227-238.

Stein A, Athreya V, Gerngross P, Balme G, Henschel P, Karanth U, Miquelle D, Rostro S, Kamler J, and Laguardia A. 2016. Panthera pardus. The IUCN Red List of Threatened Species 2016: e. T15954A50659089. Gland: IUCN.

Suchodolski JS. 2011. Companion animals symposium: microbes and gastrointestinal health of dogs and cats. Journal of Animal Science 89:1520-1530.

Suchodolski JS. 2016. Diagnosis and interpretation of intestinal dysbiosis in dogs and cats. Veterinary Journal 215:30-37.

Suchodolski JS, Foster ML, Sohail MU, Leutenegger C, Queen EV, Steiner JM, and Marks SL. 2015. The fecal microbiome in cats with diarrhea. PLOS ONE 10:e0127378.

Suchodolski JS, Markel ME, Garcia-Mazcorro JF, Unterer S, Heilmann RM, Dowd SE, Kachroo P, Ivanov I, Minamoto Y, Dillman EM, Steiner JM, Cook AK, and Toresson L. 2012. The Fecal Microbiome in Dogs with Acute Diarrhea and Idiopathic Inflammatory Bowel Disease. PLOS ONE 7:e51907. 10.1371/journal.pone.0051907

Sunquist M, and Sunquist F. 2002. Wild cats of the world. Journal of Wildlife Management 67:658.

Tian Y, Wu J, Smith AT, Wang T, Kou X, and Ge J. 2015. Population viability of the Siberian Tiger in a changing landscape: Going, going and gone? Ecological Modelling 222:3166-3180.

Tremaroli V, and Bäckhed F. 2012. Functional interactions between the gut microbiota and host metabolism. Nature 489:242-249.

Tun HM, Brar MS, Khin N, Jun L, Hui RK, Dowd SE, and Leung FC. 2012. Gene-centric metagenomics analysis of feline intestinal microbiome using 454 junior pyrosequencing. Journal of Microbiological Methods 88:369376.

Turnbaugh PJ, Bäckhed F, Fulton L, and Gordon JI. 2008. Diet-induced obesity is linked to marked but reversible 
596

597

598

599

600

601

602

603

604

605

606

607

608

609

610

611

612

613

614

615

616

617

618

619

620

621

622

623

624

625

626

627

628

629

alterations in the mouse distal gut microbiome. Cell Host \& Microbe 3:213-223.

Turnbaugh PJ, Ley RE, Mahowald MA, Magrini V, Mardis ER, and Gordon JI. 2006. An obesity-associated gut microbiome with increased capacity for energy harvest. Nature 444:1027.

Uphyrkina O, Johnson WE, Quigley H, Miquelle D, Marker L, Bush M, and O'Brien SJ. 2001. Phylogenetics, genome diversity and origin of modern leopard, Panthera pardus. Molecular Ecology 10:2617-2633.

Van der Waaij D, Berghuis-de Vries J, and Lekkerkerk-Van der Wees J. 1971. Colonization resistance of the digestive tract in conventional and antibiotic-treated mice. Epidemiology \& Infection 69:405-411.

Wang Q, Garrity GM, Tiedje JM, and Cole JR. 2007. Naive Bayesian classifier for rapid assignment of rRNA sequences into the new bacterial taxonomy. Applied \& Environmental Microbiology 73:5261.

Wang T, Feng L, Yang H, Han B, Zhao Y, Juan L, Lü X, Zou L, Li T, and Xiao W. 2017. A science-based approach to guide Amur leopard recovery in China. Biological Conservation 210:47-55.

White JR, Nagarajan N, and Pop M. 2009. Statistical methods for detecting differentially abundant features in clinical metagenomic samples. PLoS computational biology 5:e1000352.

Wu H, Wan QH, and Fang SG. 2004. Two genetically distinct units of the Chinese sika deer (cervus nippon): analyses of mitochondrial DNA variation. Biological Conservation 119:183-190.

Wu X, Zhang H, Chen J, Shang S, Yan J, Chen Y, Tang X, and Zhang H. 2017. Analysis and comparison of the wolf microbiome under different environmental factors using three different data of Next Generation Sequencing. Scientific Reports 7:11332.

Yang H, Dou H, Baniya RK, Han S, Guan Y, Xie B, Zhao G, Wang T, Mou P, Feng L, and Ge J. 2018. Seasonal food habits and prey selection of Amur tigers and Amur leopards in Northeast China. Scientific Reports 8:6930. 10.1038/s41598-018-25275-1

Yasushi M, Otoni CC, Steelman SM, Olga B, Steiner JRM, Jergens AE, and Suchodolski JS. 2015. Alteration of the fecal microbiota and serum metabolite profiles in dogs with idiopathic inflammatory bowel disease. Gut Microbes 6:33-47.

Zhang H, and Chen L. 2010. Phylogenetic analysis of 16S rRNA gene sequences reveals distal gut bacterial diversity in wild wolves (Canis lupus). Molecular Biology Reports 37:4013-4022.

Zhang H, Liu G, Chen L, and Sha W. 2015. Composition and diversity of the bacterial community in snow leopard (Uncia uncia) distal gut. Annals of Microbiology 65:1-9.

Zhao N, Li M, Luo J, Wang S, Liu S, Wang S, Lyu W, Chen L, Su W, and Ding H. 2017. Impacts of canine distemper virus infection on the giant panda population from the perspective of gut microbiota. Scientific Reports 7:39954.

Zheng J, Zhang Y, Wang Y, and Dong D. 2009. The characteristics of plant distribution and diversity in the middle section of Taihang Mountain. Henan Science. 


\section{Figure 1 (on next page)}

Rarefaction curves (A) and rank abundance curves (B).

The $\mathrm{x}$-axis of rarefaction curves indicates the sequences number selected randomly from samples and the $y$-axis indicates the observed species number (OTUs). The curves in (A) tend to be flat reflect that the sequencing data size is rational. In rank abundance curves $(B)$, the $x$-axis indicates the order number ranked by the OTUs abundance while $y$-axis shows the relative abundance of OTUs. The higher the richness of the species, the larger the span of the curve on the horizontal axis. In the vertical direction, the smoother the curve, the more uniform the species distribution. 
PeerJ

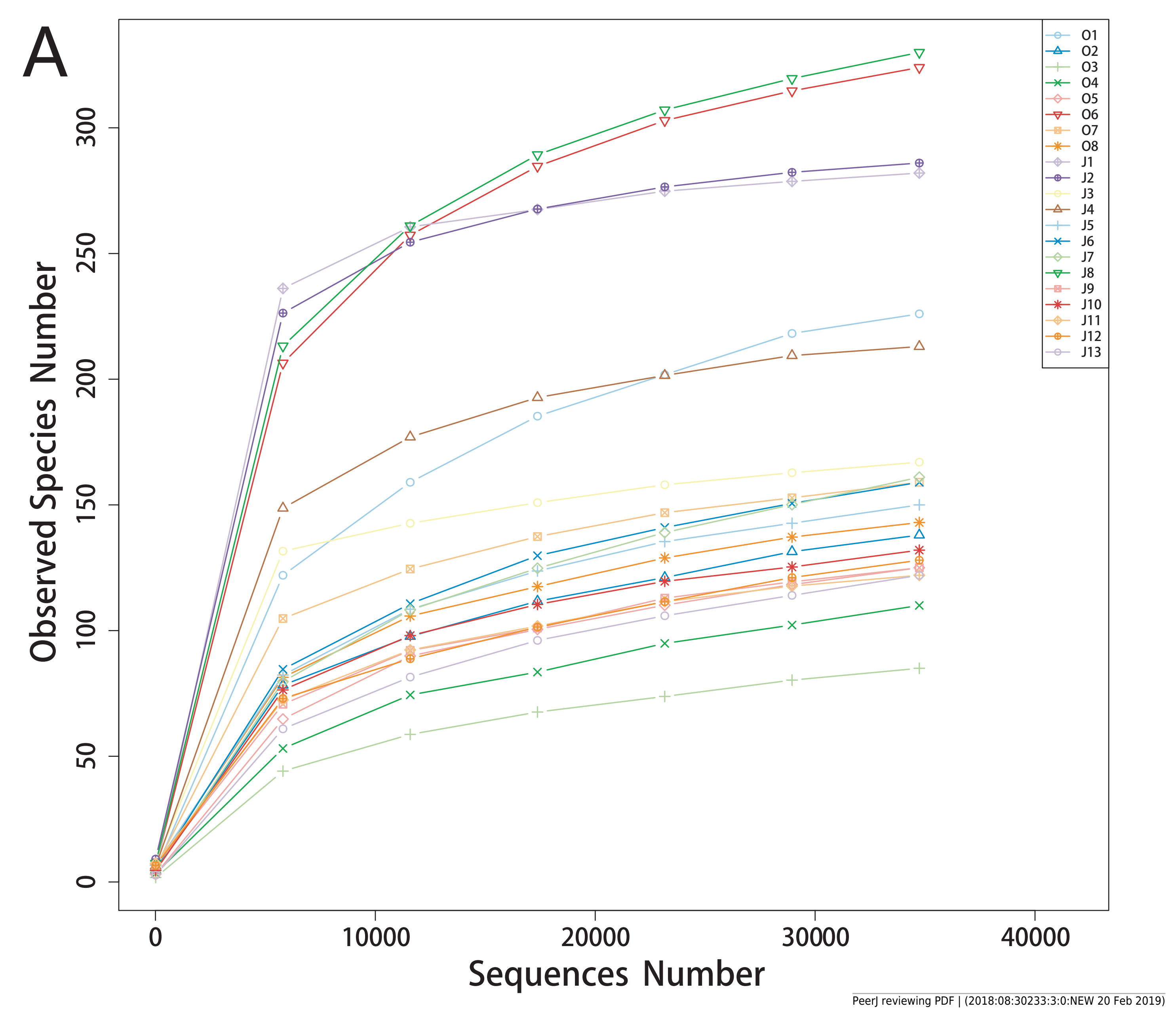

Manuscript to be reviewed

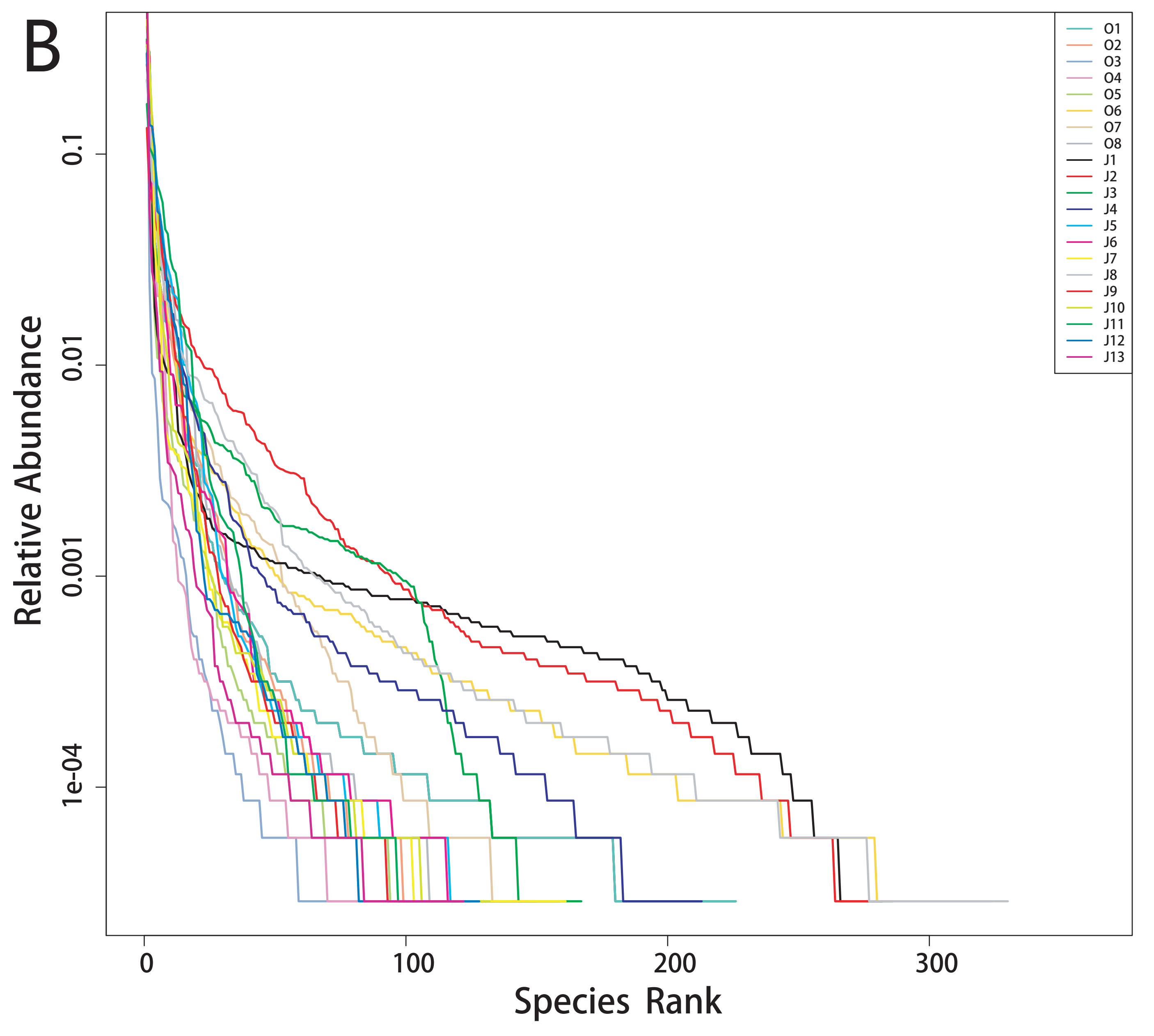




\section{Figure 2 (on next page)}

Fecal bacterial composition of Amur leopard and North Chinese leopard at the phylum level.

The top ten bacterial phyla chosen according to the results of species annotations were ranked by the relative abundance in each sample or group. The $x$-axis and $y$-axis represents the information of samples and relative abundance respectively. 


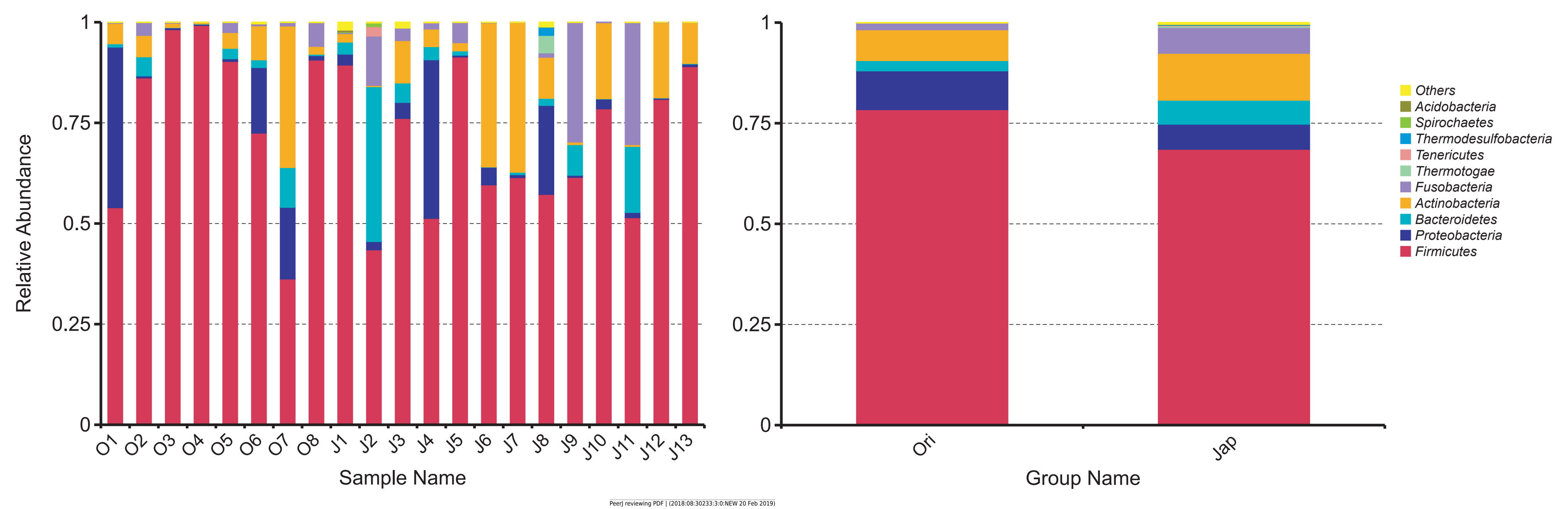




\section{Figure $\mathbf{3}$ (on next page)}

The heatmap of clustering for species richness (A) and UPGMA clustering trees with relative abuandance in phylum level (B).

The heatmap of clustering for species richness (A) illustrates the bacterial distribution among different fecal samples of leopards. The bacterial phyla were clustered for their relative abundance. The $x$-axis represents each sample, and the $y$-axis represents the relative percentage of each bacterial phyla. The Z-value (-4 to 4), displayed by color intensity, is the relative abundance of the sample and the difference in the average relative abundance of all samples divided by the standard deviation of all samples in the classification. In (B), the UPGMA clustering trees were generated with the weighted and unweighted Unifrac distance and then we integrated the trees with the relative abundance of species among all samples in phylum level. The relative abundance of species at phylum changed as the main composition phyla changed based on different Unifrac distance. 


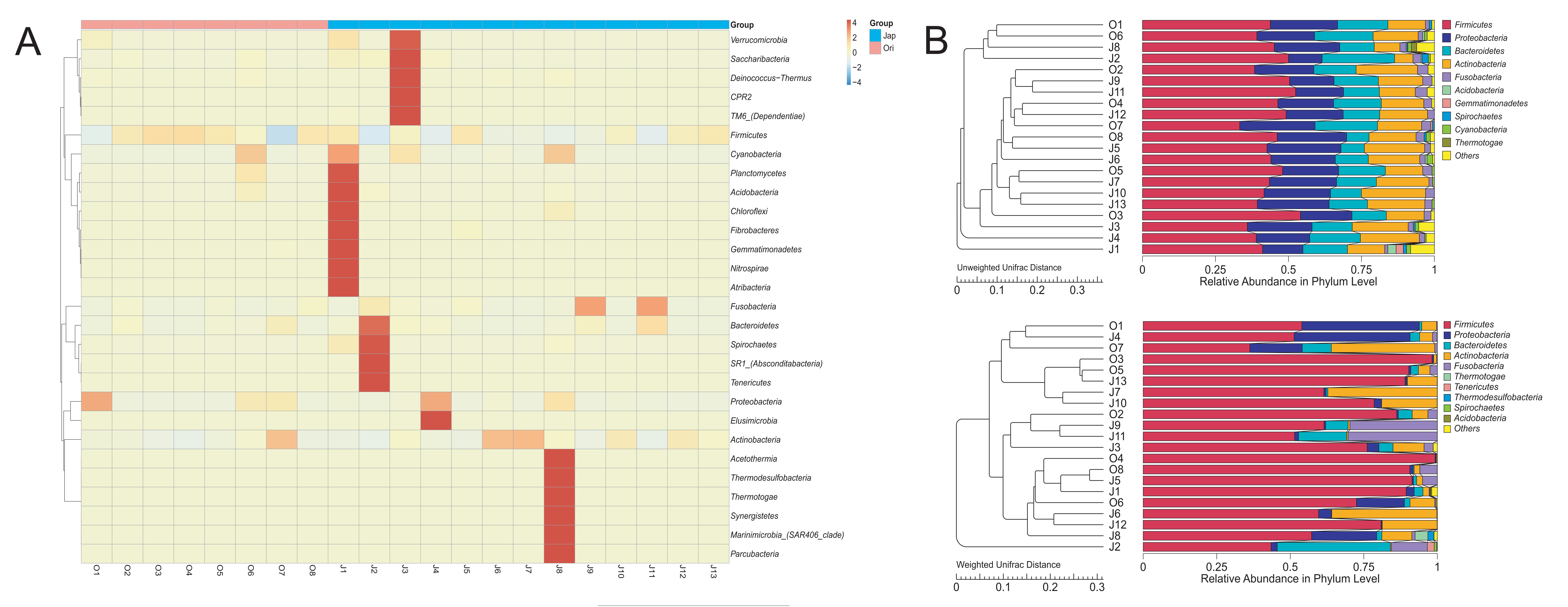




\section{Figure 4(on next page)}

Comparisons of alpha (observed species and Shannon index) and beta-diversity (with weighted and unweighted Unifrac distance matrix) between Amur leopard and North Chinese leopard fecal samples. 
PeerJ

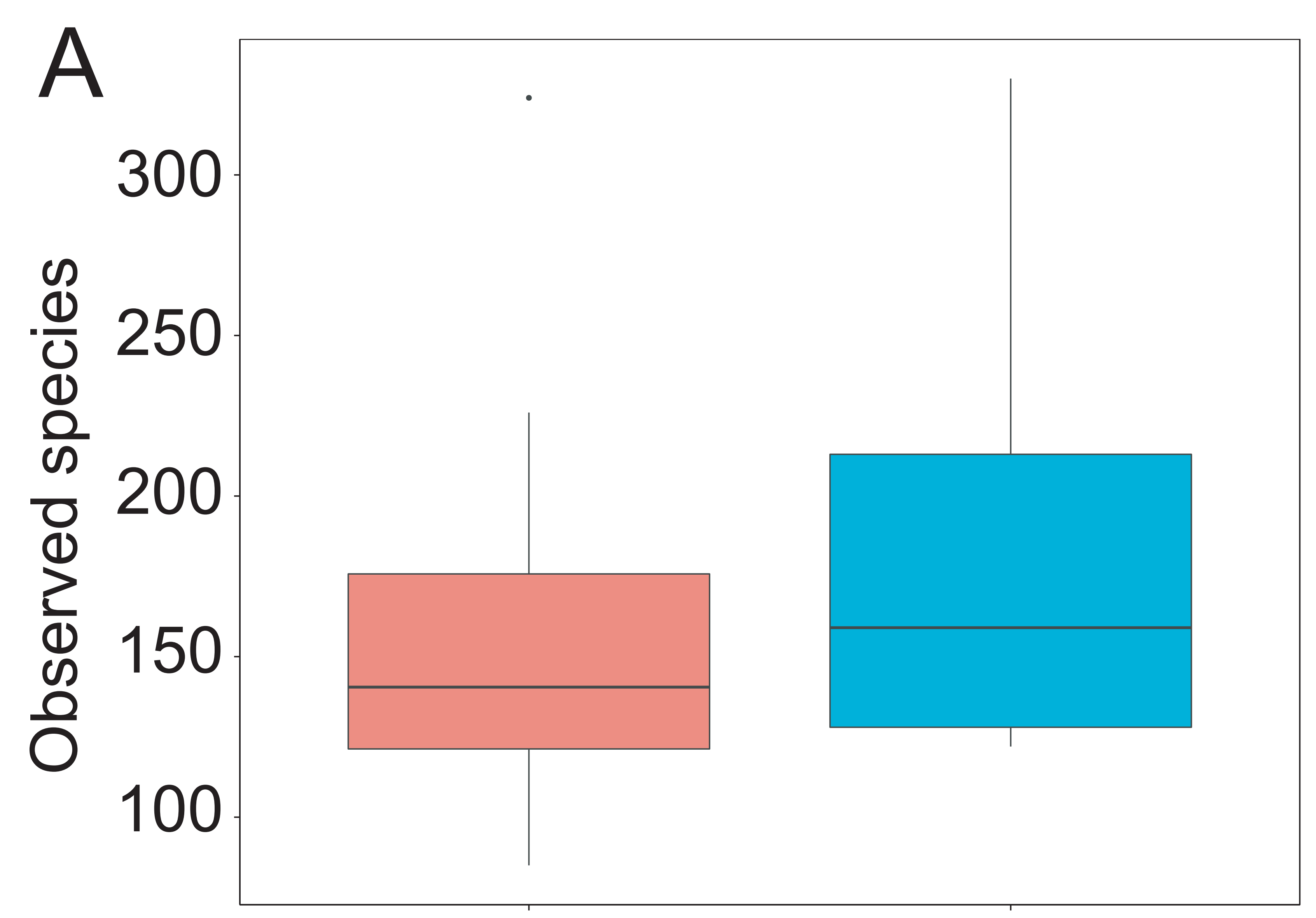

B

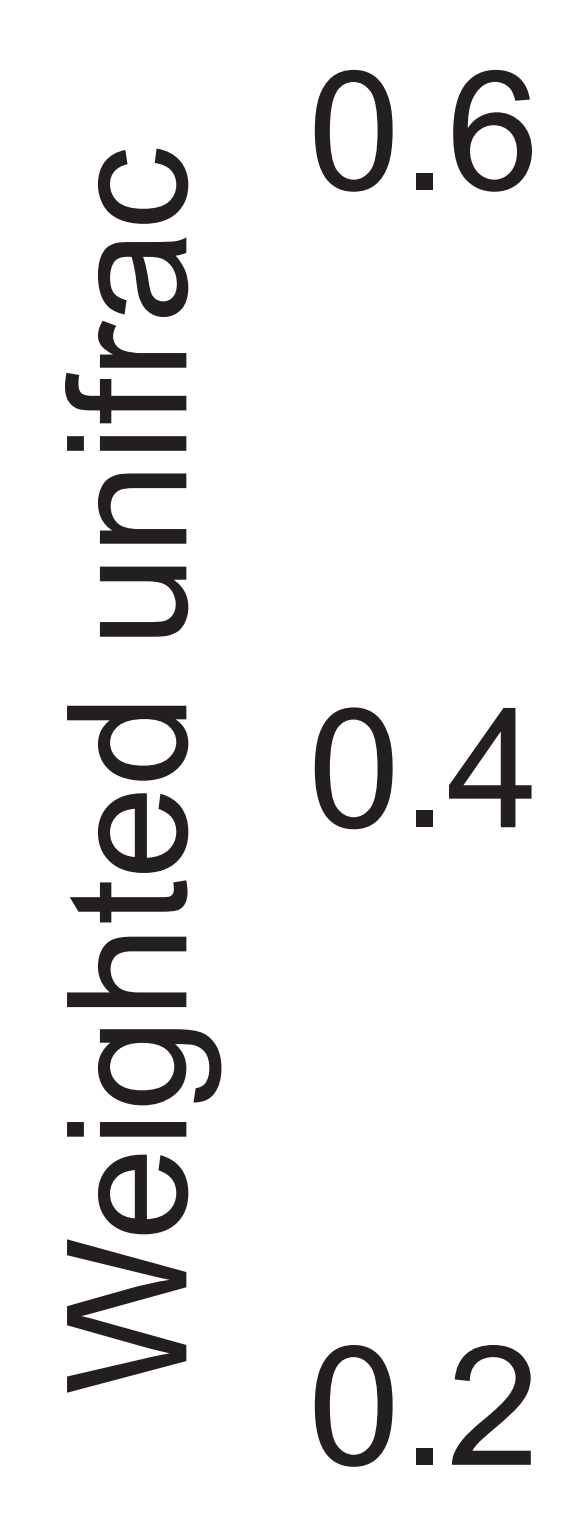

Manuscript to be reviewed
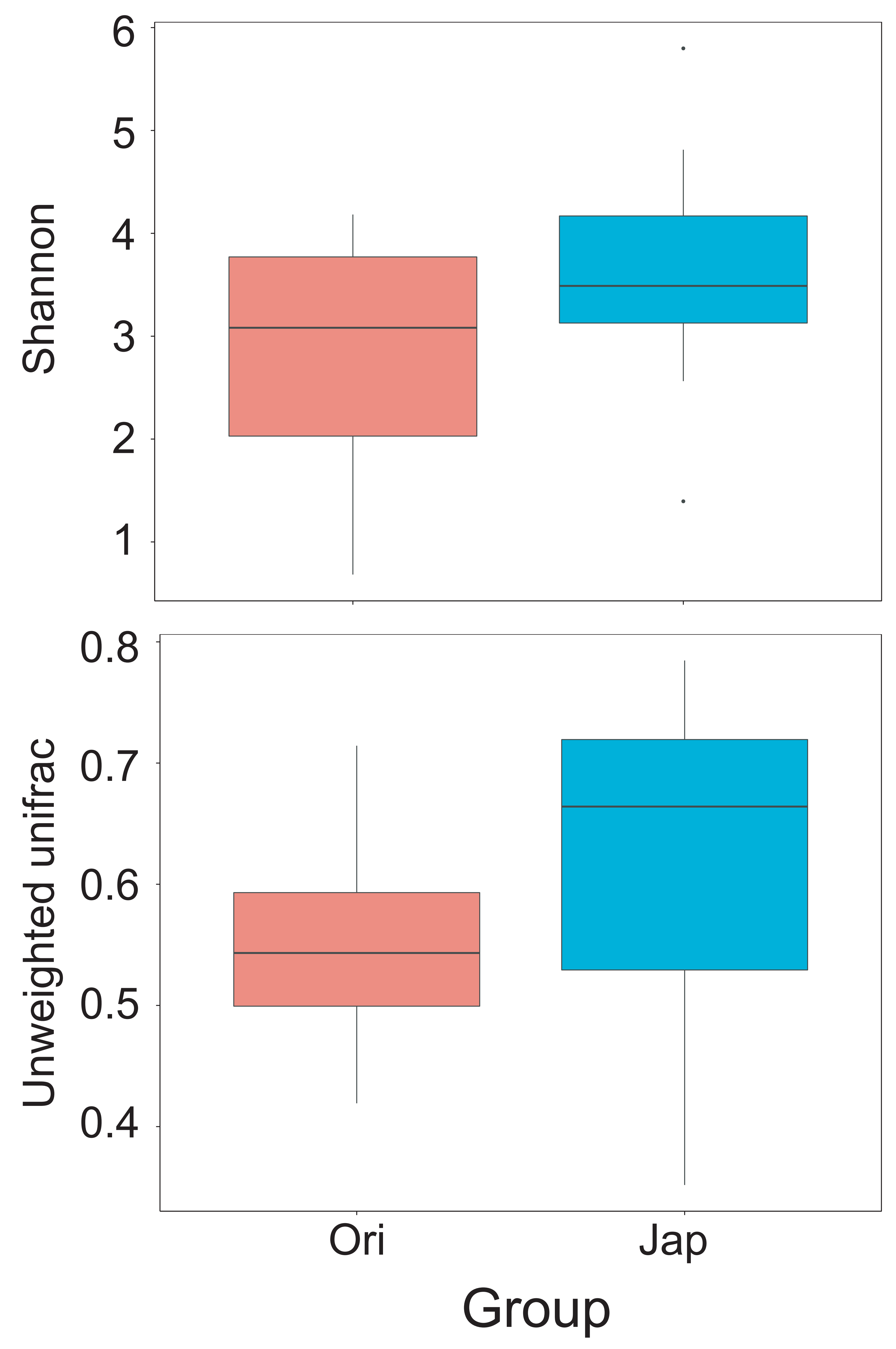
Figure $\mathbf{5}$ (on next page)

NMDS, PCA and PCoA of fecal bacterial community structures of Amur leopard and North Chinese leopard.

The yellow points represent Amur leopard and the blue squares represent North Chinese leopard. For PCOA (A) and (B) were analyzed with weighted Unifrac distance and unweighted Unifrac distance respectively. All the points in Fig. 5 are scattered which indicates that no significant differences were found between the two subspecies. 
PeerJ

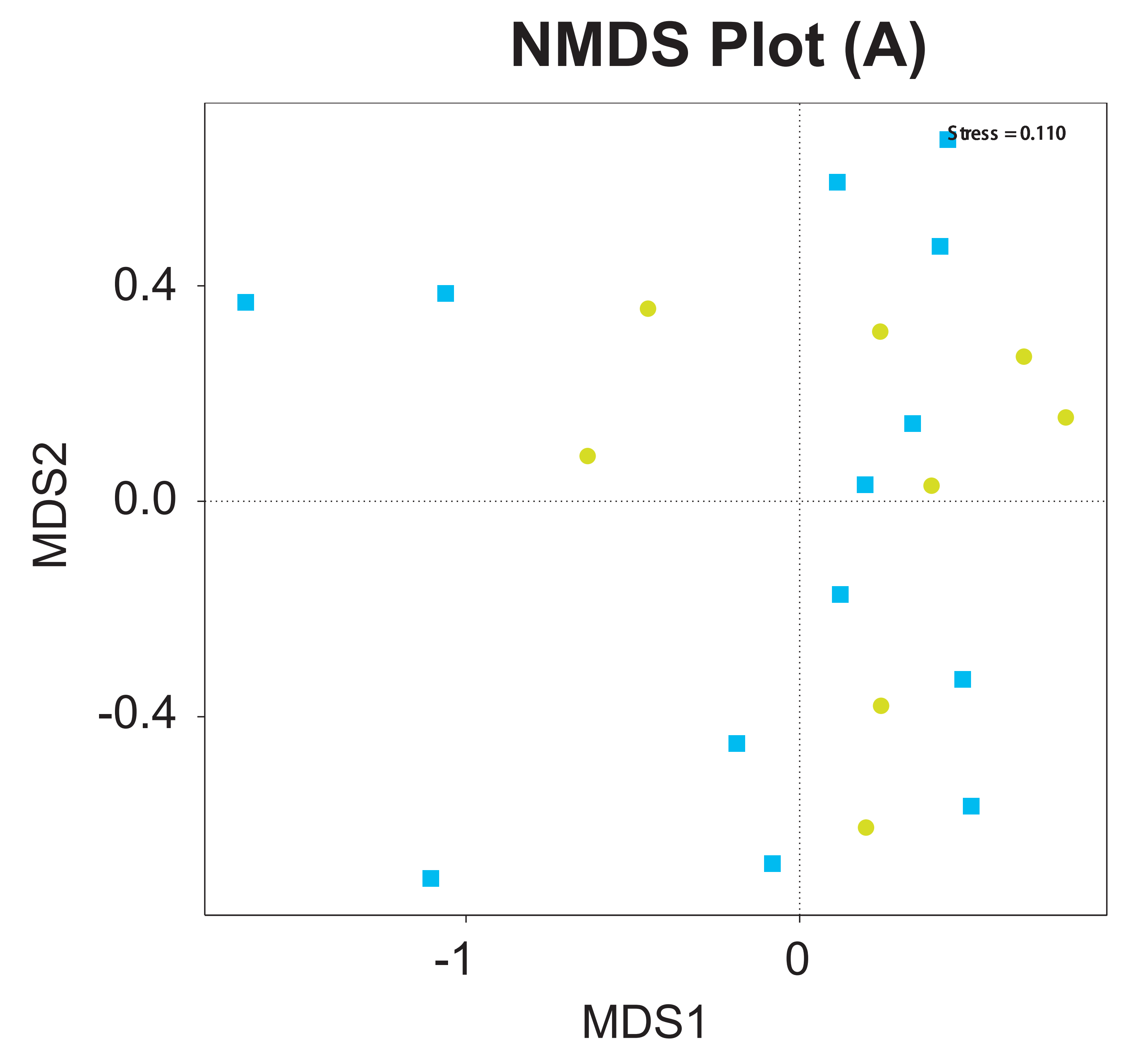

PCoA - PC1 vs PC2 (C)

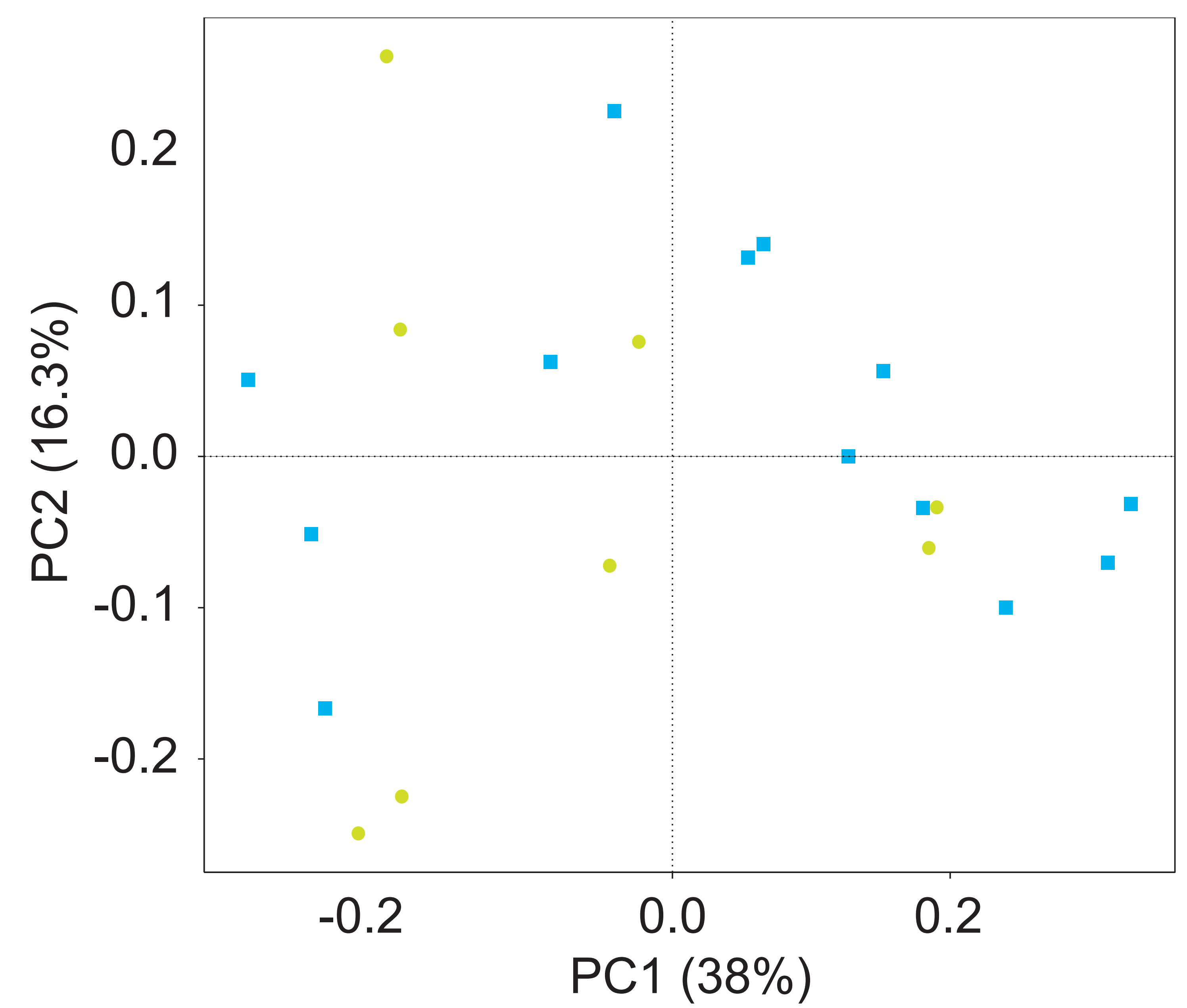

Manuscript to be reviewed

PCA Plot (B)

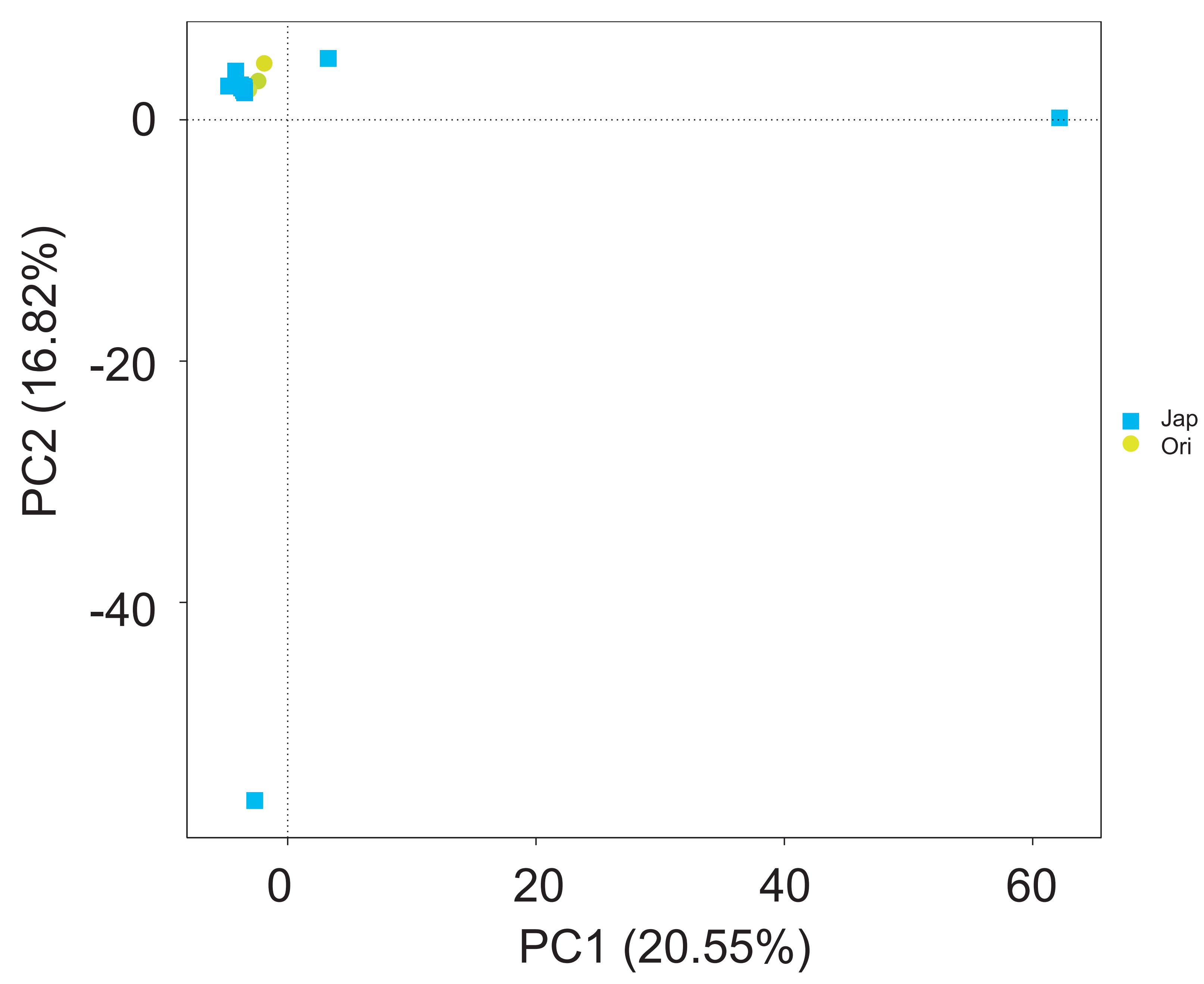

PCoA - PC1 vs PC2 (D)

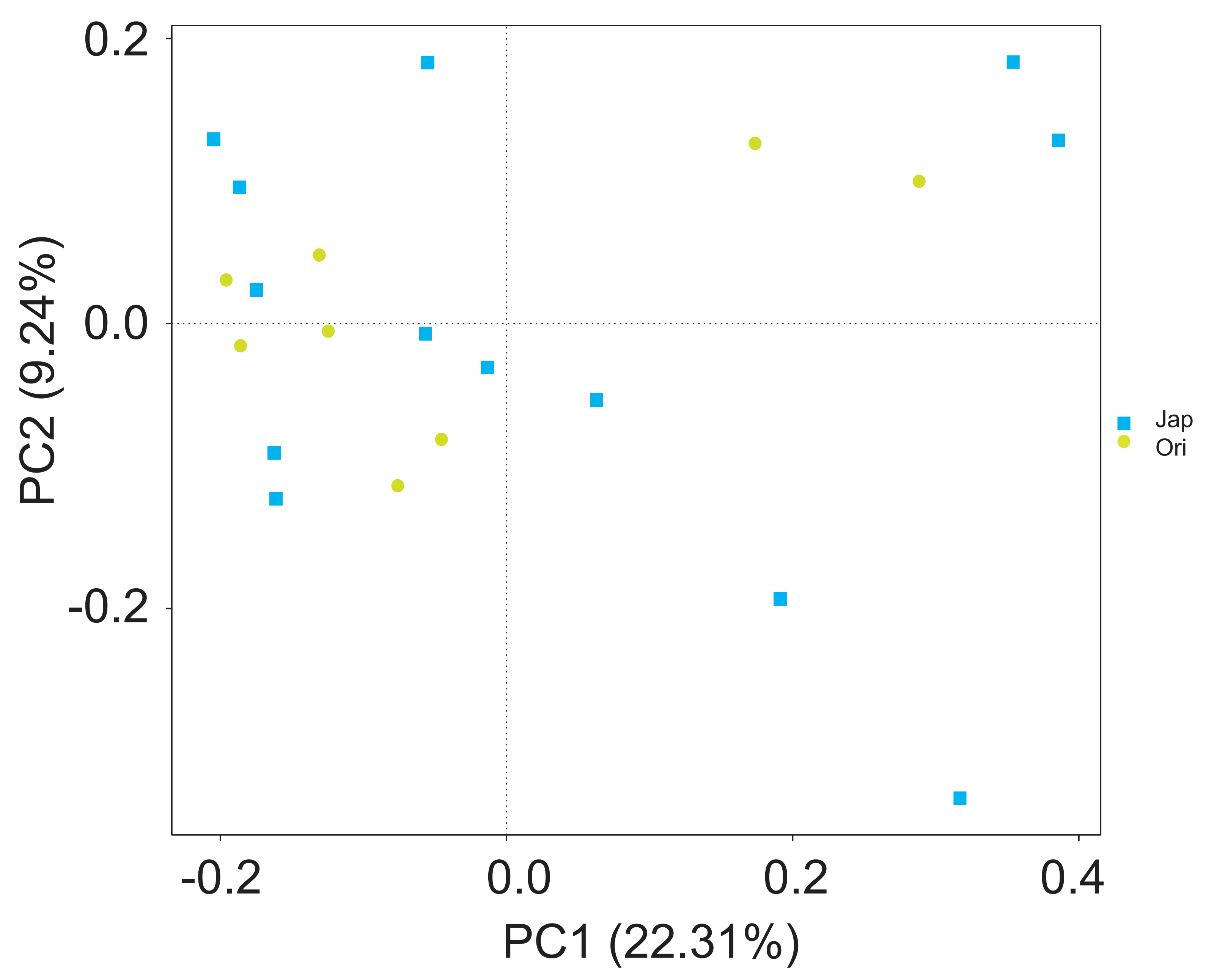




\section{Table $\mathbf{1}$ (on next page)}

Alpha-diversity of fecal microbiota in Amur leopard and North Chinese leopard feces. 
1

\begin{tabular}{ccccccc}
\hline Sample & $\begin{array}{c}\text { Observed } \\
\text { species }\end{array}$ & Shannon & Simpson & Chao1 & ACE & $\begin{array}{c}\text { Goods } \\
\text { coverage }\end{array}$ \\
\hline O1 & 226 & 3.205 & 0.788 & 248.521 & 258.106 & 0.999 \\
O2 & 138 & 2.959 & 0.747 & 173.455 & 190.37 & 0.999 \\
O3 & 85 & 0.683 & 0.146 & 108.4 & 117.38 & 0.999 \\
O4 & 110 & 2.137 & 0.649 & 161.25 & 163.516 & 0.999 \\
O5 & 125 & 1.704 & 0.433 & 144.077 & 157.104 & 0.999 \\
O6 & 324 & 4.183 & 0.867 & 350.757 & 351.019 & 0.999 \\
O7 & 159 & 3.875 & 0.85 & 173.04 & 181.306 & 0.999 \\
O8 & 143 & 3.736 & 0.867 & 172.75 & 174.05 & 0.999 \\
J1 & 282 & 3.489 & 0.666 & 294.364 & 289.486 & 1 \\
J2 & 286 & 5.798 & 0.961 & 300.056 & 298.907 & 0.999 \\
J3 & 167 & 4.412 & 0.855 & 194.273 & 195.119 & 0.999 \\
J4 & 213 & 4.086 & 0.868 & 237.474 & 233.225 & 0.999 \\
J5 & 150 & 3.871 & 0.888 & 170.036 & 178.518 & 0.999 \\
J6 & 159 & 3.128 & 0.786 & 202 & 203.286 & 0.999 \\
J7 & 161 & 2.563 & 0.722 & 246.55 & 234.682 & 0.998 \\
J8 & 330 & 4.813 & 0.909 & 370.886 & 364.072 & 0.998 \\
J9 & 125 & 3.454 & 0.854 & 151.4 & 160.056 & 0.999 \\
J10 & 132 & 2.946 & 0.791 & 145.5 & 156.117 & 0.999 \\
J11 & 122 & 4.169 & 0.919 & 139.105 & 146.006 & 0.999 \\
J12 & 128 & 3.473 & 0.853 & 308.167 & 201.223 & 0.999 \\
J13 & 122 & 1.395 & 0.333 & 157.286 & 164.553 & 0.999 \\
\hline
\end{tabular}

2 